\title{
A Study of Measurements of Spinal Canal at the Level of Lower Three Lumbar Vertebra by 16 Slice CT Scanner in Nepalese Population
}

\author{
Mukesh Mallik $^{1}$, Keshav Paudel $^{1}$, Nuwadatta Subedi ${ }^{2}$, Sanjay Sah $^{1}$, Anish Subedee $^{1}$, Deepak Adhikari ${ }^{1}$ \\ ${ }^{1}$ Department of Radiodiagnosis, Chitwan Medical College \\ ${ }^{2}$ Department of Forensic Medicine and Toxicology, College of Medical Sciences
}

\author{
Correspondence \\ Mukesh Mallik \\ Department of Radiodiagnosis, Chitwan \\ Medical College \\ E-mail:mallikcmc@gmail.com
}

\begin{abstract}
Background and Objective: The study was conducted with the objectives to establish the measurements of spinal canal and lumbar vertebra at L3 to L5 region in Nepalese population. Methodology: It is a crosssectional study among 36 patients (17 males and 19 females) having age variation from 20-60years whose abdomen was scanned by GE bright speed 16 slice CT scanner with slice thickness $10 \mathrm{~mm}$ and then reconstructed at $1.2 \mathrm{~mm}$ for images in different body plains for the measurement of spinal canal. Results: Almost all the parameters increase from L3 to L4 to L5 but the difference is more between L4 and L5 than between L3 and L4 except in vertebral body width (VBW) where it increases smoothly, however canal body ratio (CBR) remained constant at 0.6. All the parameters were larger in males than in females except antero-posterior dimension of canal in transverse section (APT) which is larger in females. It also shows that none of the parameters vary significantly depending upon sex except vertebral body width (VBW) at L3 which is $39.041 \pm 4.1334$ in males and $36.474 \pm 2.8509$ in females $(p=0.036)$.Conclusion: Antero- posterior dimension in transverse and sagittal is almost identical but the chances of measurement error is higher in transverse due to trigonal shape of canal so AP diameter should be done in sagittal section as this is consistent and measures $14 \mathrm{~mm}$ at $\mathrm{L} 3,14 \mathrm{~mm}$ at $\mathrm{L} 4$ and $15 \mathrm{~mm}$ at L5 hence defining average antero-posterior canal dimension in sagittal section to be $14 \mathrm{~mm}$ but CBR constant at 0.6 .
\end{abstract}

Key words: CT Scan, lumbar vertebra, canal body ratio

Citation: Mallik M, Paudel K, Subedi ND, et al. A study of measurements of spinal canal at the level of lower three lumbar vertebra by 16 slice CT scanner in Nepalese population. JCMS Nepal 2014;10(4):6-11

\section{INTRODUCTION}

The spinal canal is formed by the vertebral body anteriorly, the pedicles laterally, the laminae posterolaterally, and the base of the spinous process posteriorly. This arrangement forms a protective ring for the neural tube. At the inferolateral aspect of each vertebra, a bony tunnel, the neural foramen, is appreciated bilaterally. The walls of the foramina are formed by the vertebral pedicle superiorly, the pedicle of the next vertebral body inferiorly, the facets posteriorly, and the disko-vertebral junction anteriorly. Back pain results from many causes, including degenerative and congenital spinal stenosis, neoplasm, infection, trauma, and inflammatory or arthritic processes. 
CT scans provides a noninvasive, non-operatordependent method of direct imaging of the spinal canal without injection of intra thecal contrast and is better than MRI for bone detail as in osteophytes. CT and myelography are important in patients who, for technical reasons, cannot enter the MRI scanner (e.g., those with pacemakers or claustrophobia) or in patients whose MRI findings do not correlate with clinical symptoms. ${ }^{1}$

Though there is a wide variation in the capacity of spinal canal in patients who are clinically and radiologically normal. It is said that those with smaller canals are more likely to have symptoms from nerve root compression. ${ }^{2} \mathrm{By}$ determining normal ranges of spinal canal diameter we can make early diagnosis in persons who have lower diameters of spinal canal. These persons are predisposed to spinal canal stenosis, which is a major cause of spinal radiculopathies. $^{3}$

Spinal stenosis is defined as the narrowing of central spinal canal. The two main types of spinal stenosis i.e. developmental and degenerative are differentiated with the help of both MRI and CT. ${ }^{4}$ Anatomically stenosis may be classified as central, lateral or combined, based on radiographic measurements. Precise anatomic classification of the site of stenosis (central canal, lateral recess and/ a neural foramina) is perhaps the most practical approach and helps to determine the nature and extent of surgical treatment. ${ }^{5}$

Eisenstein's two large Anatomic studies of skeleton found the lower anteroposterior diameter of spinal canal in adults to be $12 \mathrm{~mm}$ and $13 \mathrm{~mm}$. CT scan measurement of lumbar spine demonstrated a mean AP canal diameter between $12 \mathrm{~mm}$ and $14 \mathrm{~mm}$ with a measurement of $11.5 \mathrm{~mm}$ considered small. ${ }^{6} \mathrm{On}$ CT scan, electronic measurement of the sagittal diameter of the normal bony canal are $11.5 \mathrm{~mm}^{4}$ so it is necessary to study dimension of canal.

Recently, it has been pointed out that instead of measuring the vertebral canal for evaluating the degree of stenosis, it would be more reliable if the ratio of vertebral canal and vertebral body i.e. canal body ratio $(\mathrm{C} / \mathrm{B})$ is taken as index for calculating the degree of stenosis. ${ }^{7}$

Ample of studies over lumbar interpedicular distances from plain radiographs have been reported among various ethnic group and both sexes as in Maharashtra population ${ }^{7}$ white Americans, ${ }^{8}$ Nigerians, ${ }^{9,10}$ and in Gujarathis. ${ }^{11}$ Therefore, the present study aims to establish a normal range of measurements of lumbar vertebrae in Nepalese population in Chitwan.

\section{MATERIAL AND METHOD}

Materials for this prospective study were collected from the CT scans of the patients coming to the department of Radio diagnosis and imaging in Chitwan Medical College, Chitwan, Nepal. This descriptive cross sectional study was performed on total of 36 patients (17 males and 19 females) who were scanned with the age ranging from 20-60 years irrespective of sex. Subjects selected were patients referred to perform CT scan of abdomen having no low back pain or other abnormalities attributable to lumbar spine.

Study being based on hazardous electromagnetic radiation, no scan was carried out for the purpose of study alone. Patients below the age of 20years and above the age of 60years were excluded because former may be at growing stage and later may have age related degenerative or other problems. Patients having sciatic pain with or without pain in the back, having previous history of back surgery and patients having osteophytes or other abnormalities in lumbar vertebrae were also not included. Patients having developmental anomalies, any trauma or vertebral fracture and known case of lordosis, scoliosis or kyphosis were also avoided in this study.

\section{Data Collection Tools and Method}

Data was collected systematically in a detailed Performa developed for the lumbar spine problem evaluation. Exclusion was done by history taking, 
complaint by patients, and provisional diagnosis given by clinicians as per the relevant papers brought by patients. Examining tool was 16 channeled scanner of General Electronic (GE) model named" bright speed". Measurement was done in work station provided by GE Company itself with application version sdc 4.2. Data was collected by the researcher alone to minimize error and produce consistency.

\section{Scanning Technique}

Examinations were done in GE bright speed model having multiple reconstruction system of minimum slice thickness $0.6 \mathrm{~mm}$ or $1.2 \mathrm{~mm}$. Patients under this study were scanned for abdomen so volumetric helical scan were done with $10 \mathrm{~mm}$ slice thickness and then reconstructed with $1.2 \mathrm{~mm}$ thickness.

In the work station, available data were reformatted for MPR (multi planar reconstruction) under iterative reconstruction technique and image at multiple plane were obtained. Transverse diameter of the lumbar spinal canal was measured as the minimum distance between the medial surfaces of the pedicles of a given vertebra (Interpedicular distance) (Jones $\&$ Thomson, 1968) $)^{12}$. The transverse diameter of the vertebral body was measured at the mid-waist level, where they were the narrowest. Anteroposterior diameter was measured from mid-point of posterior wall of vertebral body to the anterior border of the point of union of the two laminae. AP diameter of canal was also measured at mid-sagittal level. Analysis was done using SPSS (Statistical package for Social sciences) version 16.0. Observation were recorded, analyzed and discussed.

Paired samples t- test was used to analyze the mean dimensions of the parameters at different levels. Independent samples t- test used to analyze the mean dimensions of the parameters of males and females at the same level. $\mathrm{P}$ value of $<0.05$ was considered to be significant.

\section{RESULT}

Among the total 36 cases studied, 17 (47.22\%) were males and 19 (52.78\%) were females. The age distribution showed that most of the cases belong to 21 to 30 years and 31 to 40 years age group containing $11(30.56 \%)$ subjects each. The age group of 41 to 50 and 51 to 60 years contained $7(19.45 \%)$ cases each.

Table 1: Measurements of dimensions at $3^{\text {rd }}, 4^{\text {th }}$ and $5^{\text {th }}$ lumbar vertebral level

\begin{tabular}{|l|l|l|l|l|}
\hline Parameters & \multicolumn{1}{|c|}{$\begin{array}{c}\text { Mini- } \\
\text { mum }\end{array}$} & $\begin{array}{c}\text { Maxi- } \\
\text { mum }\end{array}$ & \multicolumn{1}{|c|}{ Mean } & $\begin{array}{c}\text { Std. } \\
\text { Devia- } \\
\text { tion }\end{array}$ \\
\hline L3APT & 11.1 & 19.8 & 14.51 & 1.93 \\
\hline L3MLT & 17.1 & 28.0 & 23.06 & 2.44 \\
\hline L3VBW & 30.2 & 46.5 & 37.69 & 3.70 \\
\hline L3APS & 11.1 & 19.3 & 14.83 & 1.97 \\
\hline A4APT & 11.1 & 19.2 & 14.74 & 1.89 \\
\hline L4MLT & 19.6 & 36.1 & 25.08 & 3.60 \\
\hline L4VBW & 30.9 & 49.3 & 40.19 & 3.86 \\
\hline L4APS & 10.9 & 19.1 & 14.87 & 2.08 \\
\hline L5APT & 12.9 & 22.9 & 16.08 & 2.19 \\
\hline L5MLT & 21.8 & 38.4 & 29.67 & 4.49 \\
\hline L5VBW & 32.6 & 54.4 & 43.42 & 5.43 \\
\hline L5APS & 10.6 & 21.1 & 15.53 & 2.57 \\
\hline
\end{tabular}

The table 1 shows almost all the parameters increase from L3 to L4 to L5 but the difference is more between L4 and L5 than between L3 and L4 except in vertebral body width (VBW) where it increases smoothly.

Canal body ratio (CBR) calculation shows that mean CBR at L3 was $0.6159303 \pm 0.07702455$ while the mean CBR at L4 was $0.6263503 \pm 0.08232949$. When analyzing the mean CBR at these two levels, it was seen that the mean CBR was not significant ( $p$ value of 0.335 ). Similarly the mean CBR at L5 was $0.6910228 \pm$ 0.11917204 . However, after analyzing the mean CBR at the levels of L4 and L5 it was observed to be significant ( $p$ value of 0.001 ).

The mean APT at L3, L4 and L5 was 14.508, 14.744 and 16.081 respectively with SD of 1.9298 , 1.8947 and 2.1924 at corresponding level 
respectively. Analysis of data at L3 and L4 showed to be non-significant ( $p$ value of 0.178 ) and at L4 and L5 it was revealed to be significant ( $\mathrm{p}$ value of $<0.001)$.

Mean medio-lateral dimension of canals in Transverse section (MLT) at the level of L3 is 23.056 with SD 2.4434, at L4 it is 25.083 with SD 3.5960 and at L5 it was 29.669 with SD 4.4894. Data analysis at the level of L3 and L4 and at L4 and L5 both suggested it to be significant ( $p$ value $<0.001$ ).

The measurements of vertebral body width (VBW) at the level of L3, L4 and L5 in transverse section were $37.686,40.189$ and 43.422 with SD of $3.6987,3.8596$ and 5.433 respectively which on analysis was found to be significant $(\mathrm{p}<0.001$ ) each.

Measurements of antero-posterior dimension of canal in sagittal (APS) section at the level of L3, L4, and L5, after analysis depicted that mean differences are significant at L4 and L5 ( $p=0.026)$ and non-significant at L3 and L4 ( $\mathrm{p}=0.827)$.

\section{DISCUSSION}

Importance of the radiographic measurement of the spinal canal was first emphasized by This study has been done by 16 channeled computed tomography of GE bright speed. We gathered data and processed them for analysis. The age group selected for the present study is very much similar as the age group used for earlier such studies, so that the ethnic differences in the trait could be well compared. In the present study, attempt has been made to determine standard normal minimum interpedicular distance as a preliminary to clinical investigation of transverse spinal canal stenosis.

\section{Transverse Diameter of Spinal canal}

As per Table no.2, it is seen that, the mean transverse diameter of the spinal canal goes on increasing from L3 to L5. This increasing trend of transverse diameter of spinal canal is also seen in both the sexes however, the mean values are lower in females than males. This difference in males and females is statistically not significant. Considering the calculated range, the limits of narrowing of spinal canal or intraspinal tumors can be suspected as described below. Spinal canal in males is the smallest in Nepalese at L3 but is similar to that of Nigerians at L4 and similar to white Americans at L5.

This variation in mean from a particular may be due to small number of sample in our study. But so far as canal in females are concerned, they are smaller at almost all the three levels except at L5 where present study shows similarity with western Maharashtra people, ${ }^{7}$ who have similar body habitus as that of Nepalese.

Table 2: Transverse diameter of the spinal cord

\begin{tabular}{|c|c|c|c|c|c|c|}
\hline \multirow{2}{*}{ Authors } & \multicolumn{3}{|c|}{$\begin{array}{c}\text { Transverse diameter } \\
\text { of spinal canal in } \\
\text { males }\end{array}$} & \multicolumn{3}{|c|}{$\begin{array}{c}\text { Transverse diameter } \\
\text { of spinal canal in } \\
\text { females }\end{array}$} \\
\hline & L3 & L4 & L5 & L3 & L4 & L5 \\
\hline $\begin{array}{l}\text { Hinck et al. }{ }^{8} \\
\text { (White Ameri- } \\
\text { cans 1962) }\end{array}$ & 26.8 & 27.6 & 30.7 & 25.4 & 26.4 & 29.0 \\
\hline $\begin{array}{l}\text { AmonooKuofi } \\
\text { HS.9 (Nigerians } \\
\text { 1982) }\end{array}$ & 24.5 & 26.0 & 28.7 & 23.7 & 25.4 & 28.4 \\
\hline $\begin{array}{l}\text { Piera et al. }{ }^{13} \\
\text { (Spanish1988) }\end{array}$ & 29.4 & 30.9 & 34.3 & 27.5 & 29.5 & 33.4 \\
\hline $\begin{array}{l}\text { Sudha Chha- } \\
\text { bra et al. }{ }^{10} \\
\text { (North Indians, } \\
\text { 1991) }\end{array}$ & 29.7 & 35.5 & 37.4 & 27.3 & 30.1 & 34.4 \\
\hline $\begin{array}{l}\text { A.S. Jadhavet } \\
\text { al (Western } \\
\text { Maharashtra, } \\
\text { India 2011) }\end{array}$ & 27.1 & 29.0 & 32.4 & 23.6 & 25.4 & 28.6 \\
\hline $\begin{array}{l}\text { Nirvan AB et } \\
\text { al. }{ }^{1} \\
\text { (GujaratisIndia } \\
\text { 2005) }\end{array}$ & 26.4 & 27.9 & 30.9 & 25.8 & 27.0 & 29.8 \\
\hline $\begin{array}{l}\text { Present study } \\
\text { (Nepalese2011) }\end{array}$ & 23.8 & 26.2 & 30.8 & 22.4 & 24.1 & 28.7 \\
\hline
\end{tabular}

\section{Transverse Diameter of Vertebral Body}

Table no. 3shows the increasing diameter of vertebral body from L3 to L5. This is probably because of the increase in load bearing from above downwards. It is also seen that the transverse diameter of vertebral body is larger in males than in females. The differences between the means of the two are 
statistically not significant except at L3 where males have significantly high difference may be because all the data have been collected at once.

Despite the pattern of body size increment is similar to other groups as in previous study the mean transverse diameters of vertebral bodies in males of present study is smallest as compared to other races might be because of body built up and nature of load bearing requirement. The comparison among females is also similar which suggests us that vertebral body width in males and females of Nepal is smaller than Negros and white Americans may be due to body habitus.

Table 3: Transverse diameter of the vertebral

\begin{tabular}{|l|c|c|c|c|c|c|}
\hline \multirow{2}{*}{ Authors } & \multicolumn{2}{|c|}{$\begin{array}{l}\text { Transverse diameter } \\
\text { of vertebral body in } \\
\text { females }\end{array}$} & \multicolumn{3}{|c|}{$\begin{array}{c}\text { Transverse diameter } \\
\text { of vertebral body in } \\
\text { males }\end{array}$} \\
\cline { 2 - 6 } & L3 & L4 & L5 & L3 & L4 & L5 \\
\hline $\begin{array}{l}\text { AmonooKuofi } \\
\text { HS (Nigerians } \\
\text { 1982) }\end{array}$ & 42.5 & 45.7 & 50.5 & 45.8 & 49.6 & 52.8 \\
\hline $\begin{array}{l}\text { Sudha Chha- } \\
\text { bra et al. } \\
\text { (North Indians, } \\
\text { 1991) }\end{array}$ & 44.2 & 47.0 & 55.6 & 48.3 & 51.5 & 59.4 \\
\hline $\begin{array}{l}\text { Nirvan AB et } \\
\text { al. } \\
\text { (Guja- } \\
\text { ratis2005) }\end{array}$ & 42.9 & 45.0 & 49.6 & 44.0 & 46.4 & 51.5 \\
\hline $\begin{array}{l}\text { A.S. Jadhavet } \\
\text { al } \\
\text { (Western Ma- } \\
\text { harashtra, } \\
\text { India 2011) }\end{array}$ & 41.8 & 44.4 & 47.4 & 48.7 & 51.5 & 55.8 \\
\hline $\begin{array}{l}\text { Present study } \\
\text { (Nepalese2011) }\end{array}$ & 39.04 & 41.5 & 44.3 & 36.5 & 39.0 & 42.7 \\
\hline
\end{tabular}

\section{Canal Body Ratio}

The size of vertebral body should vary proportionately with the build of the individual. In order to find out the relationship between the canal and body size, a comparison was made by finding the ratio between the mean transverse diameter of canal and mean transverse diameter of vertebral body at various vertebral levels. The results showed that as the size of vertebral body changes, the transverse diameter of canal also varied, maintaining a ratio of
0.6 at each vertebral level in both the sexes. Thus any deviation of the canal body ratio from its approximate value of 0.6 to one or the other side indicates possibility of intraspinal tumour and stenosis. Table 4 shows comparison of canal body ratio between different populations of the world which is approximately constant at 0.6 in most of the study groups.

Canal Body Ratio is constant at approximately 0.6 at all the levels when mean was calculated in overall samples irrespective of sex but it was 0.7 at L5 in males in Nepalese may be because of splitting of subjects according to sex. However results agree with previous study.

Table 4: Canal body ratio in males and females

\begin{tabular}{|c|c|c|c|c|c|c|}
\hline \multirow[t]{2}{*}{ Authors } & \multicolumn{3}{|c|}{$\begin{array}{c}\text { Transverse diameter } \\
\text { of vertebral body in } \\
\text { females }\end{array}$} & \multicolumn{3}{|c|}{$\begin{array}{c}\text { Transverse diameter } \\
\text { of vertebral body in } \\
\text { males }\end{array}$} \\
\hline & $\mathbf{L 3}$ & L4 & L5 & L3 & L4 & L5 \\
\hline $\begin{array}{l}\text { AmonooKuofi } \\
\text { HS }^{9} \text { (Nigerians } \\
\text { 1982) }\end{array}$ & 0.53 & 0.52 & 0.54 & 0.56 & 0.56 & 0.56 \\
\hline $\begin{array}{l}\text { Sudha Chha- } \\
\text { bra et al. }{ }^{10} \\
\text { (North Indians, } \\
\text { 1991) }\end{array}$ & 0.61 & 0.63 & 0.63 & 0.62 & 0.64 & 0.63 \\
\hline $\begin{array}{l}\text { Nirvan AB et } \\
\text { al. } 11 \\
\text { (Guja- } \\
\text { ratis2005) }\end{array}$ & 0.60 & 0.60 & 0.60 & 0.60 & 0.60 & 0.60 \\
\hline $\begin{array}{l}\text { A.S. Jadhavet } \\
\text { al }^{7} \\
\text { (Western Ma- } \\
\text { harashtra, } \\
\text { India 2011) }\end{array}$ & 0.56 & 0.56 & 0.58 & 0.56 & 0.57 & 0.61 \\
\hline $\begin{array}{l}\text { Present study } \\
\text { (Nepalese2011) }\end{array}$ & 0.61 & 0.63 & 0.70 & 0.61 & 0.62 & 0.68 \\
\hline
\end{tabular}

\section{Antero-Posterior Diameter of Spinal Cord}

In the present study mean APT as per table 5 at L3, L4 and L5 was 14.508, 14.744 and 16.081 respectively with SD of 1.9298, 1.8947 and 2.1924 at corresponding level respectively which corresponds to the previous research however diameter at L5 is significantly high might be due to trigonal shape of canal in transverse section. This logic is supported by canal diameter in sagittal section (15.525) as it 
not highly significant large compared to transverse section (16.081). These values are true for both males and females as the AP diameter being comparable in both sexes.

\section{CONCLUSION}

Spinal canal stenosis is the major cause of backache. Stenosis can be diagnosed by measuring spinal canal dimension i.e. interpedicular distance but canal body ratio is more accurate method for diagnosis as it remains constant at 0.6 in normal adults and do not have significant variation due to race or body habitus despite canal and body increases craniocaudally.

Antero- posterior dimension in transverse and sagittal is almost identical but the chances of measurement error is higher in transverse due to trigonal shape of canal so AP diameter should be done in sagittal section as this is consistent and measures $14 \mathrm{~mm}$ at $\mathrm{L} 3,14 \mathrm{~mm}$ at $\mathrm{L} 4$ and $15 \mathrm{~mm}$ at $\mathrm{L} 5$ hence defining average antero-posterior canal dimension in sagittal section to be $14 \mathrm{~mm}$.

\section{REFERENCES}

1. Haaga JR, Boll D. CT and MRI of the Whole Body, $5^{\text {th }}$ edi Volume 2. 2008,Mosby.

2. Vinay KV, Vishal K. A study of transverse diameter of lumbar spinal canal in normal Indian using CR-35x digitizer. JLS2012:2(2);30-5.

3. Midia M, Miabi Z. Quantitative size assessment of the lumbar spinal canal by computed tomography. Acta Medica Iranica 2007:45(5);377-82.

4. Ahmad T. A study of lumbar canal by MRI in clinically symptomatic and asymptomatic subjects. Journal of Anatomical Society of India2011;60(2):184-7.DOI: 10.1016/ S0003-2778(11)80022-5.

5. Binder DK, Schmidt MH, Weinstein PR. Lumbar spinal stenosis. Semin Neurol 2002 Jun;22(2):157-66.

6. Chatha DS. MRI criteria of developmental lumbar spinal stenosis revisited. Bulletin of the NYU Hospital for Joint Diseases 2011;69(4):303-7.

7. Jadhav AS, Katti AS, Herekar NG. Transverse Diameter of Lumbar Vertebrae in Western Maharashtra Population. International Journal of Recent Trends in Science And Technology 2011;1(3):130-7.

8. Hinck VC, Clark WM, Hopkins CE. Normal interpedicular distance (minimum\& maximum) in children \& adults. Amer J Roentgen 1966;97:141-53.DOI: 10.2214/ ajr.97.1.141.

9. AmonooKuofi HS. Maximum \& minimum lumbar interpedicular distance in normal adults Nigerians. J Anat 1982;135:225-33.

10. Sudha C, Gopinath K, Chibber SR. Transverse diameter of lumbar vertebral canal in North Indians. J Anat Soc India 1991;41(1):25-32.

11. Nirvan AB, Pensi CA, Patel JP, et al. A study of interpedicular distance of the lumbar vertebrae measured in plain antero posterior radiography. J Anat Soc India 2005;54(2): 58-61.

12. Jones RAC, Thomson JLG. The narrow lumbar canal. A clinical and radiological review. J Bone\& Joint Surg 1968;50:595-605.

13. Piera V. Rodriguez A, Cobos A, et al. Morphology of the lumbar vertebral canal. Acta Anatomic 1988;131:35-40. 